\title{
Robert Legrand, La guerre d'indépendance américaine et La Fayette
}

Abbeville, F. Faillart éditeur, 2006, 222 p., $22 €$.

\section{Marc Belissa}

\section{OpenEdition}

\section{Journals}

Édition électronique

URL : https://journals.openedition.org/ahrf/11286

DOI : 10.4000/ahrf.11286

ISSN : 1952-403X

Éditeur :

Armand Colin, Société des études robespierristes

Édition imprimée

Date de publication : 1 septembre 2007

Pagination : 214-215

ISSN : 0003-4436

Référence électronique

Marc Belissa, «Robert Legrand, La guerre d'indépendance américaine et La Fayette », Annales historiques de la Révolution française [En ligne], 349 | juillet-septembre 2007, mis en ligne le 29 décembre 2009, consulté le 01 juillet 2021. URL : http://journals.openedition.org/ahrf/11286 ; DOI : https://doi.org/ 10.4000/ahrf.11286 
logique des événements. Or, n'est-ce pas sur la question de la réciprocité dans la logique de la transparence (déclarations fiscales des sujets contre transparence des comptes) que la monarchie échoua ? Soucieux de rendre compte de toutes les occasions où la notion a été évoquée, Arnaud Decroix en oublie quelque peu les enjeux fondamentaux de son sujet. Il n'en demeure pas moins que l'on mesure bien à travers cet ouvrage l'évolution des exigences de l'opinion publique animée par les remontrances parlementaires (Keith Baker).

On utilisera donc l'ouvrage d'Arnaud Decroix comme un formidable outil bibliographique, mais l'on ne se leurrera pas sur les conditions d'avancée de l'histoire des finances publiques. Celle-ci exige d'entrer un minimum dans la logique des sciences de gestion, sous peine de voir ce pan essentiel de l'histoire politique échapper entièrement à la discipline historique.

Marie-Laure LEGAY

Robert Legrand, La guerre d'indépendance américaine et La Fayette, Abbeville, F. Faillart éditeur, 2006, 222 p., $22 €$.

Il s'agit de l'ultime ouvrage de Robert Legrand, membre de la Société des études robespierristes, décédé en août 2006 (voir l'hommage de Claude Mazauric publié dans le numéro 347 de la revue). Chercheur autodidacte, s'intéressant autant à la poésie qu'à l'histoire de la Picardie et à la généalogie, Robert Legrand travaillait encore à ce nouveau livre quelques semaines avant de disparaître à l'âge de quatre-vingt-treize ans, d'où le caractère parfois un peu inachevé et décousu de l'ouvrage. On ne cherchera évidemment pas ici une nouvelle somme historiographique sur La Fayette et sur son rôle dans la guerre d'Indépendance américaine, mais plutôt le travail d'un amateur passionné par son sujet. Robert Legrand entend comprendre pourquoi le personnage de La Fayette a suscité, selon lui, autant d'appréciations négatives de la part de ses contemporains et des historiens de la Révolution. C'est donc un exercice de réhabilitation dans lequel le jugement personnel joue évidemment un grand rôle et l'auteur s'identifie souvent à son sujet d'étude, parlant même parfois de « notre armée » ou de «nos escadres " pour désigner les soldats français en Amérique. La structure et la forme de l'ouvrage ne sont pas universitaires et peuvent parfois surprendre le lecteur habitué aux normes en vigueur dans les publications académiques. Ainsi, certains développements sont présentés sous forme de notes (par exemple le chapitre III sur la guerre maritime). Louvrage est divisé en dix-huit chapitres : les huit premiers sont consacrés à la période de la guerre américaine, les dix suivants à la carrière politique de La Fayette, de son retour en France à sa mort. La première partie de l'ouvrage s'intéresse également au corps expéditionnaire français en Amérique et notamment aux officiers qui ont accompagné La Fayette. La seconde partie est moins détaillée. À noter le chapitre XIII "Vérités et contre vérités " qui entend faire un florilège des écrits contemporains et historiques sur La Fayette. Robert Legrand utilise abondamment les très nombreux ouvrages (pas toujours de grande qualité, voire pour certains exécrables) publiés sur La Fayette et Washington pour dresser un 
tableau vivant des représentations de La Fayette et de son rôle dans la guerre d'indépendance.

Lentreprise de réhabilitation de La Fayette pourra ne pas convaincre, mais il faut sans doute la voir comme un témoignage de la passion que portait son auteur à la période révolutionnaire.

Marc BELISSA

Jennifer Ngaire Heuer, The Family and the Nation. Gender and Citizenship in Revolutionary France, 1789-1830, Ithaca, Cornell University Press, 2005, VIII-256 p., ISBN 978-0-8014-4286-5, 34.95\$.

The Family and the Nation pose la question du lien entre classe de sexe et droits et devoirs patriotiques. La famille et la Nation sont des entités juridiques qui, toutes deux, imposent des devoirs à leurs membres, au premier rang desquels l'obéissance à l'autorité souveraine. Les problèmes engendrés par cette double allégeance vont être considérables lorsque, dès les premières années de la Révolution, famille et nation vont entrer en concurrence : comment doit agir une épouse prise entre l'injonction étatique de demeurer sur le territoire français et le devoir d'obéissance à son époux qui l'enjoint d'émigrer avec elle ? À quelle aune, au regard des peines encourues, la justice doit-elle mesurer la part de responsabilité de cette épouse obéissante et pourtant traître à sa patrie ? Telles sont quelquesunes des questions soulevées par le livre de Jennifer Ngaire Heuer qui retrace le processus par lequel la famille a progressivement été distincte de la nation, reconstruite, au sortir de la Terreur, comme une sphère à part, protégée de toute intrusion étatique, et dont les membres dépendants, tels les épouses, les enfants mineurs et les domestiques, ont acquis, au prix de l'anéantissement de leur citoyenneté, le privilège de ne plus devoir obéissance qu'à une seule autorité : celle du pater familias.

Le livre de Jennifer Heuer, qui est professeur d'histoire à l'Université de Massachusetts, Amherst, est une version retravaillée d'un $\mathrm{PhD}$ soutenu à l'université de Chicago, en 1998, sous la direction du professeur William Sewell (Foreigners, families and citizens : contradictions of national citizenship in France, 1789-1830). Il s'articule autour de trois parties et huit chapitres : I. La famille de la nation (1. Nouveaux contrats de parenté et citoyenneté, 1789-1793; 2. Le devoir pour la patrie avant tout : la Terreur); II. Vers une nation de familles : transitions vers la fin des années 1790 (3. Pères et étrangers ; 4. Genre et émigration reconsidérés) ; III. La solution napoléonienne et ses limites (5. Attacher l'épouse de Cain : le Code civil napoléonien ; 6. En regardant vers le passé : les conséquences de la mort civile ; 7. En regardant vers l'avenir : les femmes et l'application de la loi de citoyenneté ; 8. Immigration, mariage et citoyenneté pendant la Restauration).

Pendant la premic̀re période, qui s'étend de 1789 à 1794, la Nation est la première famille des citoyens. C'est à ce titre que tous et toutes sont requis de faire cesser tout lien qui pourrait entraver l'exercice des devoirs dus à la mère patrie ; et que c'est bien en vain que les femmes d'émigrés, ou émigrées elles mêmes, plaident leur innocence. Elles sont 14000 , nous dit J. Heuer, à avoir émigré ; et 50000 chefs de famille. Dès 1792, celles qui sont revenues trouvent des défenseurs de leur cause ; ceux-ci arguent que les femmes, comme les domestiques, ne sauraient abandonner leur patrie, ne sauraient trahir puisqu'ils et elles sont sans utilité dans la nation, 